\title{
ELS Journal on Interdisciplinary Studies in Humanities
}

Volume 4 Issue 1, 2021

DOI: https://doi.org/10.34050/elsjish.v4i1.11598

Homepage: journal.unhas.ac.id/index.php/jish

\section{A Genre Analysis of the Undergraduate Thesis Abstracts: Revisiting Swales' Theory of Written Discourse}

\author{
Andi Suwarni ${ }^{1 *}$, Abidin Pammu², Fathu Rahman², Noer Jihad Saleh² \\ ${ }^{1 *}$ STKIP Muhammadiyah Bone, Indonesia \\ ${ }^{2}$ Hasanuddin University, Indonesia \\ *Correspondence: andisuwarni25@gmail.com
}

\begin{abstract}
The genre analysis has become a critical study in pragmatic which forms the dialogic interaction that manifest written academic discourse socially and culturally. The aims of this study is to describe the pattern and variation of moves that appear from the undergraduate thesis abstracts at a specific college in the Bone Region. The implications of this study on educational written materials are included. Data collection comprised 45 abstracts as samples consist of 3 cohorts (2015, 2016 and 2017) of university students, each with 15 abstracts. A structure studied by Hyland (2005) was used to explain the different trends in the abstracts. Unstructured interviews with and evaluation of the students were carried out to better understand the writing skills of the students. Then data were analyzed using content analysis. The results show that most abstracts involve rhetorical gestures similar to the previous study. The moves include an initial statement, a clarification of intent and confirmation of the results and explanations for the research 's significance. The results also indicated that university students are more mindful of the logical series. Rhetorical movements and language properties needed in abstract academic learning. The aim, methodology and findings of the related paper are the most abstracts. These findings are compatible with previous studies and show that future scientists based on movement analysis that should explore the link between movement analysis results and academic teaching content. The results justify such pedagogic consequences that indicate that the student has an interest in current education research to change the teaching materials.
\end{abstract}

\section{ARTICLE HISTORY}

Published March $27^{\text {th }} 2021$

Check for updates

\section{KEYWORDS}

Confirmation, Analysis, Genre, Rhetorical Moves

\section{ARTICLE LICENCE}

(C) 2021 Universitas Hasanuddin Under the license CC BY-SA

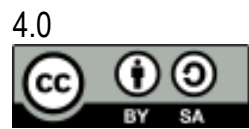

\section{Introduction}

Academics writing, for instance, the thesis abstracts, has become a vital part of education method. Since the abstract is expected at almost the undergraduate level of most universities, both in the sense of the EFL and the ESL. It is part of academic writing that needs a specific agreement that deserves an advanced research writing level. It was also considered a particular type of writing as concern in severe rules and conventions established to adjust different academic writing types and ensure that a standard text was written (Rahman, 2017). Academic papers are often standardized with the format, arrangement, structure, and presentation of topics addressed, despite their purpose. Writing academic papers is nevertheless necessary not only for the production of academic writing in universities but also for communication between businesses. Academic papers will successfully be adapted to the norm used to write business correspondence.

To complete the undergraduate students, a rigorous written thesis must be written with specific attention to the subject of study. In teaching, students need to understand some of the things that make learning academic (Rahman, 2016). First of all, writing should show readability of what academic literature tells. Also, there is also the needs to conduct research. In addition, there is also a need for a consistent explanation of the main concepts under discussion. Secondly, a clear overview of the issue being studied and the underlying theories, and the historical development of the issue must be illustrated. As part of thesis, writing an abstract is pivotal in which, whatever their academic level and background, students are needed. 
The rhetorical analysis refers to the analyzing method of texts, sources or artifacts. The texts, sources or artifacts may be written or otherwise communicated. The object of rhetorical analysis is to take account of an object, audiences, genres, place and media or design of the specific situations. In addition, the study not only refers to what is implied by relevant sources (contents). It discusses the reason why the writers wrote about (purposes), who the writer is (the background), how the piece has structured, what structure the platform is concerned with, where and when it has been written, and how the intended text has been transmitted to the audience on the subject.

One of the most challenged abstract writing at all levels of higher education is rhetorical analysis. Students often confuse rhetorical analysis with review, because both tasks are analyzing texts (Rahman, \& Weda, 2018). A rhetorical study, however, has an opinion as to whether it agrees with the subject raised. A review allows the reader, of course, to question how good or poor the text is. In order for the rhetorical study to be completed, dissimilar strategies of rhetorical are essential. These techniques include critical reading, persuasion methods, persuasive statements, arguments and avoidance of logical errors. These basic strategies are essential for the students conducting research and writing their abstracts to be taken into account.

Rhetorical analysis seeks to engage in critical thinking in order to convey an expected message effectively to a predetermined audience. Rhetorical analysis is necessary for the undergraduate student to comprise all elements that generate the abstracts which contain the aims of conducting a research, why the research is necessary, what are the results, and the implication to the area, and the educational intent the implication brings about in order to decide the intended message of a certain text successfully. The students must also establish a rhetorical structure to show their ability to compose an abstract. Rhetoric is a word which is generally used in various contexts, and may mean many things by itself. Numerous use the word to refer to speech and place and the vocabulary that becomes the nature of political rhetoric. Rhetoric can be interpreted as the way you put what you say and the forces that influence what you say. The ability to convey the intended message effectively, by argumentation, persuasion or other forms of communication, is its very core rhetoric (Prihandoko, et al, 2019; Mansyur \& Suherman, 2020) .

Ballenger (2010) confirmed that academic papers have been written for the purpose. The papers are, therefore, designed to convince, argue, explain, and compare evidence. There are also several other priorities to compose an academic article. It is necessary to emphasize the definite objective and complete it in writing to create newspapers such as journals. Consequently, writing may be debated as an academic if the specific academic aims are accomplished by producing various articles. It is crucial to think and act as an academic to provide adequate written work. The related books need to be read, critical topics addressed, and substantial details are examined to be published for this or that text (Elbow, 1995). Therefore, the writer's job is to include an efficient case, carefully crafted and backed by credible facts and proof. The writer's expertise concerning the subject under discussion will convince the audience (Hoffman \& Ford, 2009).

In essence, the abstract should reflect all sections of the undergraduate article, but it should be shortened. In other words, a person who reads the abstract must always be aware of why the study is worth doing and in what measure the values and the implications are produced. A good abstract would also make it possible for the reader to understand why the research is done, how it was done, and why it is relevant. Abstracts from scientific papers are often not written correctly, sometimes it lacks essential details and conveys a partial image. Therefore, at least the good abstract outlines several academic components, namely a clear statement of the research purpose, a succinct explanation of the methodology and data collection, statement of results and an abstract conclusion.

Despite the popularity of the abstract which is regarded as good because of its academic conventions, for some reason not many undergraduates can present the good abstract. First, the candidate lacks expertise or academic writing skills due to a variety of reasons, such as inadequate preparation or ignorance of knowledge. Second, students may have adequate knowledge, but they do not have the ability to understand writing conventions' properties. Third, students have a poor grammatical capacity to write correctly and academically. Therefore, it would be of great benefit to perform a study based on the examination of gender to determine the existing potential of students, so that intervention and change can be recommended to enhance the standard of the undergraduate thesis.

\section{Literature Review}

For several years there has been genre analysis, and numerous documentation has already been published in the literature. Weisberg (1993) said that he initiated a genre study that focuses on graduate seminars' presentation. This study was exploratory and was confined to seminars in applied life studies, particularly in animal science and agronomy at the American Southwest research center. The study included an overview of speech event components of the type, subject 
intent, environment, participants, message model, content, the sequence of the act, and rules of interaction by Saville Troike (1982).

The word 'genre' is referred to in such a study as a communication class events with a shared common goal. The genre is divided into sub-genres, such as proposals, progress reports, preliminary literature review and systematic study reports, on the basis of this understanding. The following is distributed to 10 seminars: 1) Two Ph.D. Proposals (one native speaker, one non-native speaker); 2) two progress reports, both at the Masters level (both native speakers); 3) preliminary literature reviews (one Master's, one non-native speaker, one non-native speaker Ph. D.); 4) four completed research reports (two native speaker 'Masters, one non-native speaker master's, one non-native speaker Ph. D).

The other research revealed that a Chinese plant generalist was the only encountered non-native speaker who used his entire conversational style. Another result also showed that most non-native students in this study typically did not discuss the "personal" component. In connection with non-native graduate students' participation with less advanced oral skills, a parallel curriculum with a whole course dedicated to them may be better served, currently being implemented as a series of science or technical writing courses. They should be ticked in many ways, for example, by presenting a professional autobiography, introducing a speaker, by delimiting a field of study with primary sources, debating a particular research issue or controversy; 6 ) by documenting a single literary or personal experience experiment.

Unlike Weisberg (1993), the second genus study based on oral genres, the Brett (1994) study focuses on prose. He did research on Genre Analysis representation in science research journals. For this study, he wanted to see the standard of research writing samples of twenty research papers in the field of sociology. The method used is first of all by classifying in the construction of the general organization the 20 research papers namely Introduction, Methods, Result and Discussion. Using a percentage, he counted the number pages in every part after this classification. The total number of pages for goal, Method, Results, and Discussion are $24 \%, 20 \%, 40 \%$ and $16 \%$ respectively. Thereafter, based on a communicative function or speech acts, he eventually examined the above part of the organization, each on a linguistic basis such as lexical elements and grammatical features. Derived from his findings, he argued that the resources and tasks used to enhance learning comprehension and create such a text should be reliable and punitive, so that pedagogical gender analysts do not follow models that are readily based on analyses of distressed topics. It is due to other fields that have not the same characteristics of social interaction and language development. This is because of other fields which would have numerous social practices and language realization characteristics.

Vergato (2004) conducted another study concerning the classification of the genre for English sales promotion letters in Italy. This research emphasis on the rhetorical disparity among Italian and English promotion letters. It has been believed that the cultural variations influence the types of discourse. Conventionally, written business correspondence is regarded as a routine, ritual, or even formulation. In particular, this research was based on the study of authentic Italian and English business letters in comparison. According to Vergato, sub-genres or repertoires may distinguish between business letters (purchase capital, demand, offer and promotion). Derived from the following analysis, findings indicate that both English and Italian writers exhibit differences between macro and micro-linguistics. It similarly demonstrates various ways of organizing discourse patterns and using mood and modality to communicate politeness.

\section{Method}

Research data were obtained using purposive sampling. They were derived from such criteria referred to as qualitative analysis theory (Ary et al., 2002; Miles and Huberman, 1994; Scidman, 1991). Intrinsically, collection of the data only considered abstracts written in English. A very strict supervision review undertook the compilation and presentation of this research paper. A study paper or thesis was also filed on the education that researchers actually consider on the basis of the academic background of the researcher. Each Cohort was asked to submit abstract files for 15 students. The students from each course whose academic index was above the average were carefully chosen for 15 abstracts. This is required to ensure that the abstract meets the academic criteria 'eligibility. All abstracts collected require appropriate movement and linguistic features. Not all abstracts are therefore included, particularly regarding readability and academic conventions. The data obtained were analyzed using a Hyland instrument model (1999) and presented, interpreted and concluded in a table. 


\section{Discussion Of Findings}

Adherence of the three students of the Cohort (Cohort 2015, 2016, 2017), different Cohorts choose the diverse areas of research interest within the institution as subjects of their dissertations. The important fields of study in which students are interested to compose, Speaking, Reading, Listening, Vocabulary. Grammar, Motivation, and others. The findings indicate that specific fields of study can be broadened to the amount which teachers give emphasis to the importance of materials. Compliance with the movements can be discussed in the following table (Cohort, 2015, 2016, 2017).

\begin{tabular}{|c|c|c|}
\hline \multicolumn{3}{|c|}{ Moves Profiles in Cohort (2015) } \\
\hline Category of Moves & Category of Semantics & Intentions \\
\hline \multirow{4}{*}{ Introduction } & Providing the signal & \multirow{4}{*}{$\begin{array}{l}\text { Introducing the intention and the } \\
\text { state of the art about research }\end{array}$} \\
\hline & Reemphasizing & \\
\hline & Strengthening & \\
\hline & Declaration & \\
\hline \multirow{2}{*}{ Prosedure } & Providing the sequence & $\begin{array}{l}\text { Clarifying the action process in the } \\
\text { research }\end{array}$ \\
\hline & Declaring a process & $\begin{array}{c}\text { Starting the process and } \\
\text { sequence }\end{array}$ \\
\hline \multirow{2}{*}{ Purpose } & Providing the intention & \multirow{2}{*}{ Stating the intention and objective } \\
\hline & Declaring a will & \\
\hline \multirow{2}{*}{ Declaration } & Confirming a belief & \multirow{2}{*}{ Declaring a result of research } \\
\hline & Stating the value & \\
\hline \multirow{2}{*}{ Conclution } & Confirming a belief & \multirow{2}{*}{$\begin{array}{l}\text { Strengthening a belief found from } \\
\text { the research }\end{array}$} \\
\hline & Stating the value & \\
\hline
\end{tabular}

Moves Profiles in Cohort (2016)

\begin{tabular}{|c|c|c|}
\hline Moves Category & Semantic Category & Intetion \\
\hline \multirow{4}{*}{ Introduction } & Providing a signal & \multirow{4}{*}{$\begin{array}{l}\text { Introducing the intention and the } \\
\text { state of the art about the research }\end{array}$} \\
\hline & Reemphasizing & \\
\hline & Strengthening & \\
\hline & Declaration & \\
\hline \multirow[t]{2}{*}{ Procedure } & Providing a sequence & $\begin{array}{l}\text { Clarifying the process of action in the } \\
\text { research }\end{array}$ \\
\hline & Declaring a process & Stating the process and sequence \\
\hline \multirow{2}{*}{ Purpose } & Providing the intention & \multirow{2}{*}{ Stating the intention and objectives } \\
\hline & Declaring a will & \\
\hline Declaration & $\begin{array}{l}\text { Stating the filings } \\
\text { Confirming the results }\end{array}$ & Declaring a research of result \\
\hline
\end{tabular}

Moves Profiles in Cohort (2017)

\begin{tabular}{|c|c|c|}
\hline Category of Moves & Category of Semantics & Intention \\
\hline \multirow{4}{*}{ Introduction } & Providing the signal & \multirow{4}{*}{$\begin{array}{l}\text { Introducing the intention and the } \\
\text { state of the art about the research }\end{array}$} \\
\hline & Reemphasizing & \\
\hline & Strengthening & \\
\hline & Declaration & \\
\hline \multirow[t]{2}{*}{ Procedure } & Providing a sequence & $\begin{array}{c}\text { Clarifying the process of action in the } \\
\text { research }\end{array}$ \\
\hline & Declaring a process & Stating the process and sequence \\
\hline \multirow{2}{*}{ Declaration } & Stating a finding & \multirow{2}{*}{ Declaring a result of reserach } \\
\hline & Confirming a result & \\
\hline
\end{tabular}




\begin{tabular}{ccc}
\hline Conclusion & Confirming a belief & $\begin{array}{c}\text { Strengthening a belief found from the } \\
\text { research }\end{array}$ \\
\cline { 2 - 3 } & Stating the value
\end{tabular}

\subsection{The Adherence of Micro-linguistics}

In this current study, the language dimension can be divided into macro-linguistic and micro-linguistics. A detailed comprehension of a language and its meaning is called micro-linguistics. In contrast, micro-linguistics do not focus in the impact on students of language but on the structure by analyze the elements of research such as syntax, morphology and phonetics. Hence, the micro-linguistics addresses different features of a specific language and does not offer a simple overview of how it is taught or used. Conversely, the macro-linguistics considers a language more generally. It links language in a variety of ways to society and science. For instance, macro-linguistics discusses language's position in social structures. It addresses the use of language in everyday life.

For the three cohort are concerned, the linguistic characteristics of both levels are predominant. However, there are not many topics that can be addressed in three abstract cohorts in contrast to micro linguistics. There is no phonetics, phonology and morphology in science. However, the relevance and the quality of the abstract is considered significant, provided that the students may write abstracts with the cultural or academic justification. The following tables demonstrate adherence to micro-linguistics relating to the use of grammar and vocabulary.

Table 10. Micro-linguistics Elements

\begin{tabular}{ccc}
\hline Cohort & Micro-linguistics Elements & The Abstract Location \\
\hline 2015 & $\begin{array}{c}\text { Passive and Active Voice, Past, } \\
\text { and Present Tense }\end{array}$ & $\begin{array}{c}\text { Introduction, Second Paragraph, and } \\
\text { Third Paragraph }\end{array}$ \\
\hline 2016 & $\begin{array}{c}\text { Passive and Active Voice, Past, and } \\
\text { Present Tense }\end{array}$ & $\begin{array}{c}\text { Introduction, Second Paragraph, and } \\
\text { Third Paragraph }\end{array}$ \\
\hline 2017 & $\begin{array}{c}\text { Passive And Active Voice, Past, } \\
\text { and Present Tense }\end{array}$ & $\begin{array}{c}\text { Introduction, Second Paragraph, and } \\
\text { Third Paragraph }\end{array}$ \\
\hline
\end{tabular}

\section{The Location of Abstract}

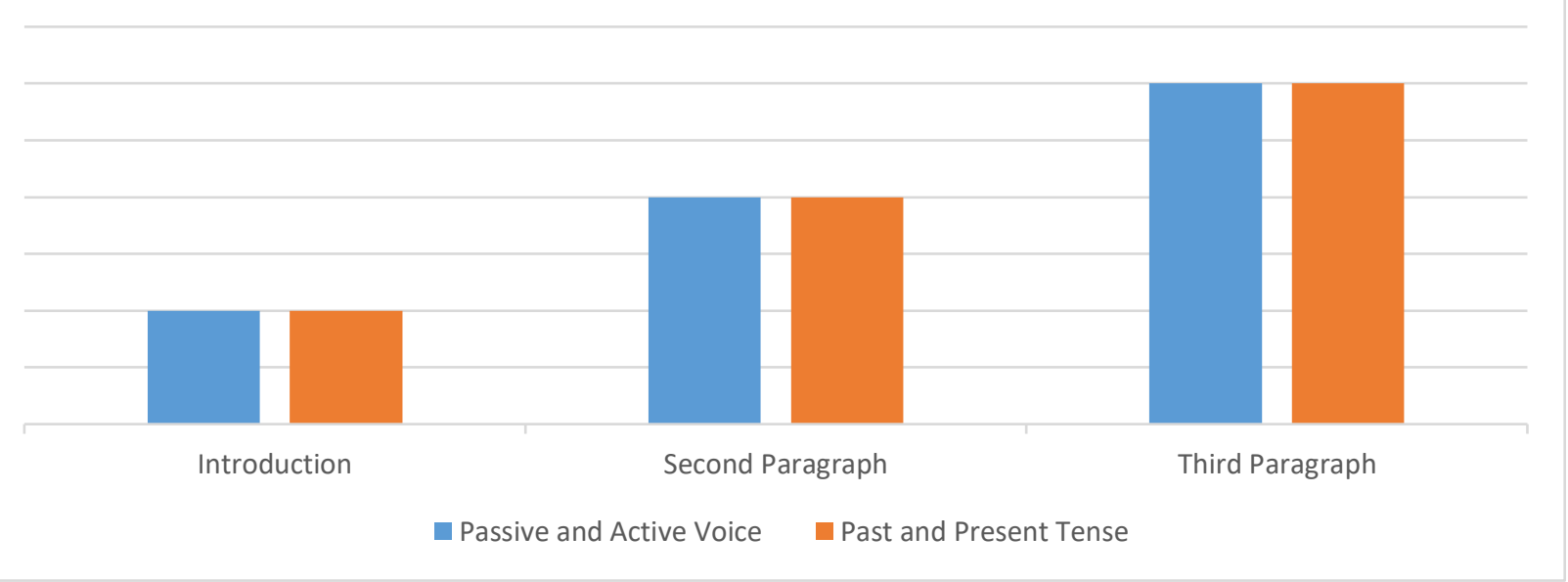

In spite of all kinds of research interests among the three Cohort Students, it seems that there are the same patterns of student in using micro-linguistic. The abstract is structured in a similar way, consisting of three paragraphs. The first section addresses the research issue and the purpose of the study - the second section deals with the data collection and sampling process and the interpretation of the results. The third paragraph deals with the consequences. The other clarification of why a similar research pattern occurs is the company's model system to construct a homogeneous abstract platform. 
As studied by Cohort students, the identification of study is dealt with in every abstract in the pattern of microlinguistics. Here, students feel it important to present the topic to readers to have a good understanding of why the topic is added. Owing to the fact that this topic will persist a significant issue, the using of the micro-linguistics elements is retained. A same pattern of micro-linguistics is followed with respect to the study goal, as students consider the goal to be achievable over time. The adherence to the findings using simple present tense in the third paragraph is identical to that in the first paragraph, suggesting that the findings will be extended over a period of time.

\subsection{Adherence of Macro-linguistics}

Macro-linguistic adherence is predominant in the three student cohorts. Writing and abstract methods are often governed by informal and formal rules that are often applied to students prior to writing. Compared to micro-linguistics, macro-linguistics prioritizes the understanding of tradition and culture and the inspiration for writing. Generally, abstract writing is a prerequisite for thesis submission and a prerequisite for a bachelor's degree. Consequently, the motivation is identical in the sense that students must pursue the trend.

Table 11. Macro-linguistics Elements

\begin{tabular}{ccc}
\hline Cohort & Macro-linguistics Element & The Writing Motives \\
\hline 2015 & $\begin{array}{c}\text { Introduction, Confirm, Admit, } \\
\text { and Reinforcing. }\end{array}$ & $\begin{array}{c}\text { Clarification Check, } \\
\text { Confirmation and Concluding }\end{array}$ \\
\hline 2016 & $\begin{array}{c}\text { Introduction, Confirm, Admit, } \\
\text { and Reinforcing. }\end{array}$ & $\begin{array}{c}\text { Clarification Check, } \\
\text { Confirmation and Concluding }\end{array}$ \\
\hline 2017 & $\begin{array}{c}\text { Introduction, Confirm, Admit, } \\
\text { and Reinforcing. }\end{array}$ & $\begin{array}{c}\text { Clarification Check, } \\
\text { Confirmation and Concluding }\end{array}$ \\
\hline
\end{tabular}

The three cohorts of students make a common claim regarding the use of macro-linguistics in the abstract of their undergraduate thesis. A topic's presentation is considered to identify and explain that the problem being discussed is an important subject for concern. Confirmation is also predominant if the writer requires the text to be read and understood. Admission is used as a critical confirmation review because the writer wants to agree that the definition needs to be investigated and addressed.

\subsection{Abstract Moves}

There are three Cohort's students recognized $(2015,2016$, and 2017) definite in using five moves. The moves using was similar to the previous study performed by Hyland (2000). There are 45 abstracts, and all of these abstracts contain rhetorical move. Students, however, have the style and the reasons for exposing their moves perhaps because of their cultural and social backgrounds. Movements are described such as introduction, intention, technique, procedure and conclusion. However, the rhetorical movement already mentioned by Hyland (2000) is usually used in abstracts by both published research papers and master thesis, the data showed differences in the use of movements. On the other hand, the majority of the abstract study follows the six-movement structure, the introduction-purpose-product-conclusionstructure.

While in some thesis abstract, the move "product" and "conclusion" are absent. It is included in the "structure movement." The numerous percentages of RA abstracts and thesis abstract containing different rhetorical moves show that RA abstracts are selective using these five basic movements. Therefore, the experts seem to concentrate more on RA abstract's influential role rather than on their informative component. In contrast, student writers seem to concentrate more on the informative role than on the thesis abstract's influential role.

\subsection{Linguistic Features}

The three linguistics features are discussed in this study. They are tense, personal pronouns, and hedges. Their criteria have been drawn as found in the abstract. The linguistic characteristics of this study are related to tense options, hedges, personal pronouns as well.

In the verbal part of the group that is named finite, the tense is coded. Finite 's interpersonal position in times is a sign of time for the speaker. Other moves, such as aims, methods, and moves of findings, tend to use past tense as the writer noticed. The abstract periods differ from past to present. The tenses use is also connected to moves. As the study of Moves placement has tendency using the present tense as writer has found. 
For a reason, methods and results of the past tense usually are used 42). In the context and conclusion, meanwhile, this tense is used. However, it is stressed that a tense choice is a rhetorical option and not a compulsory restriction. Instead of the past, one might write purpose or results, supported by Salager-Meyer when in her analysis, she concluded that the use of the time varied (Samraj, 2002).

\section{Conclusion}

The chosen abstract profiles tend to meet the criteria of what is generally known as an academic written abstract, looking at it from a certain viewpoint. The first is the fulfillment of the essential elements of the Introduction, the affirmation of the intent, the declaration of goals, and the conclusion's reinforcement. The second viewpoint requires clarity in writing, which helps the reader to appreciate the results and the consequences. Clear abstract readability, allows the reader to conclude something about the purpose of the study and why the research is worth carrying out and pursuing. In short, it meets the standard academic categories common in academic journal writing

Elements that emerge from the students' abstract comprise an intent statement, a description of the presentation, a statement of the research design, and a confirmation of the results. At the end of their paper, few abstracts were found to have announced the proposal. Schemes used in moving analyses suggest a linear assumption, so the structure of abstracts should be clarified to analyze the order of move. It is clear from the discussion in the two previous sections that there are moves in abstracts in varying quantities (including zero). This section discusses how well the fifth motion follows a linear sequence, no need for the presence or the quantity of the motion.

In comparison with the rhetorical moves of English abstract published by ESL students in applied linguistics, this study presents distinctive features because non-native speakers wrote them. They affirm the unique ability to write academic abstracts that are not so different from the ESL context. They are also able to set out appropriate rhetorical aims to reach the standard of academic literature. Whereas the five main rhetorical patterns in abstract formation are generally found in abstracts written by experts and student writers, the experts tend to make more use of these steps taken to support their posts, while student writers prefer to use all of the steps to gain further insight into the substance and structure of their thesis. Several student writers also have hedges in their abstract without considering the severity that might weaken their work's importance.

The current study demonstrates that even though students are not native speakers, they can demonstrate continuity in the abstract thesis by taking the "conclusion" step more frequently. Students' use of different hedges often provides a more reliable indicator of competency in a more consistent abstract. The present study also confirms that the disclosure of different trends in student thesis abstracts is a good predictor that the three cohorts of students retain the level of writing competence in academic writing at this institution. The standards of written abstracts of students demonstrate a greater understanding of the importance of academic literature accuracy. While these disparities may be partially due to the gender imbalance between abstracts and abstracts, they also reflect an inconsistent usage of students for disciplinary practices leading to significant pedagogical implications. Teachers need to raise awareness about the various activities involving student writers and expert writers to help other students develop their understanding of a writer who has a proper place in the debate community and encourage them to select rhetorical movements that are most effective in achieving their rhetorical goals. The findings of the research cannot be over-all due to the minimal data from this report.

\section{References}

Ballenger, B. (2010). The curious writer. USA: Longman.

Elbow, P. (1995). Being a writer vs. being an academic: A conflict in goals. College Composition and Communication, 46(1), 72-83.

Mansyur, F. A., \& Suherman, L. A. (2020). The Function of Proverbs as Educational Media: Anthropological Linguistics on Wolio Proverbs. ELS Journal on Interdisciplinary Studies in Humanities, 3(2), 271-286.

Prihandoko, L. A., Tembang, Y., Marpaung, D. N., \& Rahman, F. (2019, October). English language competence for tourism sector in supporting socio-economic development in Merauke: A Survey Study. In IOP Conference Series: Earth and Environmental Science (Vol. 343, No. 1, p. 012170). IOP Publishing.

Rahman, F. (2016). The Strategy of Teaching Literature through Language-based Methods: A Communicative Approach. In Annual Seminar on English Language Studies 2016 (Vol. 1, pp. 156-170). 
Rahman, F. (2017). Cyber literature: A reader-writer interactivity. International Journal of Social Sciences \& Educational Studies, 3(4), 156.

Rahman, F., \& Weda, S. (2018). Students' perceptions in appreciating English literary works through critical comment: A case study at Hasanuddin University and Universitas Negeri Makassar. Asian EFL Journal, 20(3), 149-172.

Samraj, B. (2014). Disciplinary variation in abstracts: The case of wildlife behaviour and conservation biology. In Academic discourse (pp. 50-66). Routledge.

Vergaro, C. (2004). Discourse strategies of Italian and English sales promotion letters. English for Specific Purposes, 23(2), 181-207.

Weissberg, B. (1993). The graduate seminar: Another research-process genre. English for Specific Purposes, 12(1), 2335. 